\title{
Factors Contributing to the Acceptance of Social Media as a Platform among Student Entrepreneurs: A Review
}

\author{
Noorlisa Maria bt A. Hamid Shokery ${ }^{1}$ \\ Noorshella Binti Che Nawi2* \\ Noorul Azwin Binti Md Nasir ${ }^{2}$ \\ Abdullah Al Mamun² \\ ${ }_{1}^{1}$ Graduate Research Assistant, Faculty of Entrepreneurship and Business, Universiti Malaysia Kelantan \\ ${ }^{2}$ Senior Lecturer, Faculty of Entrepreneurship and Business, Universiti Malaysia Kelantan \\ "Corresponding Author, Email: norshella@umk.edu.my
}

Doi:10.5901/mjss.2016.v7n2p42

\section{Abstract}

Social media has become a major development in e-commerce and a platform for student entrepreneurs, not only to sell goods and services but also to interact and connect with customers. The purpose of this paper is to identify the factors contributing to the acceptance of social media as a platform among student entrepreneurs in Malaysia. Earlier studies on social media have mostly focused on how students use social media for academic purposes. However, limited research has been done on how students or young entrepreneurs use social media as a platform to operate their business. A modified 'Unified Theory of Acceptance and Use of Technology' (UTAUT) is used as the theoretical framework to examine the level of acceptance of social media as a platform among student entrepreneurs. The key factors that contribute to the acceptance of social media as a business platform are performance expectancy, effort expectancy, social influence, facilitating condition, and perceived enjoyment.

Keywords: Social Media; Entrepreneurship; UTAUT

\section{Introduction}

The surge of social media has changed the ways in which businesses communicate and interact with consumers. This is because social media enables people around the world to interact and share products and brands with each other (Mir \& Zaheer, 2012). Social media can be classified into several types; for instance, social networking (Facebook, Myspace, and Tagged), professional networking site (Linkedln, Google+), microblogging (Twitter, Pinterest), multimedia sharing sites (Flickr, Instagram, YouTube), wikis (Wikipedia), social news (Digg, Yahoo Buzz), gaming sites (Pogo, Yahoo Games), rating sites (Yelp), consumer shopping (Groupon, Living Social), and location based services (Foursquare) (Albarran, 2013; Edwards, 2011). In addition, according to Kaplan and Haenlein (2010), social media is a term that can be described as a group of internet-based applications and web 2.0 technologies that allow users to create, modify, and generate content. In fact, social media has become an essential part of our everyday lives (Kaplan et al., 2012) and has changed the lives of individuals (Hennig-Thurau et al., 2010).

In Malaysia, the number of Internet users is recorded at 19 million, of which 16 million are social media users (We Are Social, 2014). Over the last few years, social media, such as Facebook, Twitter, and Instagram, has become a major development in e-commerce. Moreover, the growth of social media is very clear and does not show any signs of stopping or reversing (Gaber \& Wright, 2014). Therefore, social media has become a platform for student entrepreneurs, not only to sell goods and services but also to interact and connect with customers. At the same time, the study found that social media has gained tremendous popularity among Internet users and has become an integral part of consumers' behavior and lifestyle (Lee et al., 2010).

The report by Socialbakers.com (2012) found that Facebook is a popular site among Internet users in Malaysia with 13.2 million Facebook users and it is ranked $18^{\text {th }}$ in the world. This is consistent with a survey conducted by the Pew Research Centre (2014) which indicated that Facebook remains the most popular social site while other platforms such Twitter, Instagram, Pinterest, and Linkedln experience higher rates of growth. However, Malaysia is in the early stages 
when it comes to social media usage in operating a business. A survey from PwC Report indicates that a large number of Malaysian businesses are on social media, and the survey found that $69 \%$ are actively operating their business using social media. The survey also found that $58 \%$ of online sellers do not track the social media's impact on their performances, $35 \%$ do not ask for feedback on how customers expect to be engaged on the social media, and $60 \%$ do not have a social media budget. Indeed, they hardly measure or invest in social media initiatives. This study therefore aims to critically review existing literature to identify the key issues related to the adoption of social media, which will be the foundation for the conceptual model to explain how factors influence the adoption of social media among Malaysian student entrepreneurs.

\section{Reasons for Using Social Media as Business Platform}

Social media platforms such as Facebook, Twitter, Instagram, You Tube, and others, have begun to transform business activities such as marketing, advertising, and promotion (Hanna, Rohm, \& Crittenden, 2011). Additionally, social media allows users to connect with their friendship groups by adding them to the network of friendship (Ahuja \& Galvin, 2003). Witnessing the power of social media applications, many entrepreneurs use these tools to operate their business and spread their message or review their products and services. This matter also happens among student entrepreneurs who operate businesses. They choose to use social media as a business platform because in social media services, users can share their experiences with their friends to create free word of mouth marketing for the business (Mikalef, Giannakos, \& Pateli, 2013).

Furthermore, social media also provides an interactive conversation between individuals where they can share and exchange their experiences, reviews and opinions about the goods and services, which they consume. Therefore, social media has become the best platform for student entrepreneurs, not only to sell products and services, but to stay in touch with their customers (H. S. S. Lee et al.). Entrepreneurship is a process that identifies an opportunity by understanding the resource requirements, acquiring the resources, planning, and implementing (Serarols-Tarrés, Padilla-Meléndez, \& del Aguila-Obra, 2006). Hence, student entrepreneurs need to be more active in sharing the benefits derived through their entrepreneurial projects or business. Thus, social media is the best platform for them to use in order to operate their business.

A previous study by J. Brown, Broderick, and Lee (2007) shows that users tend to be more trusting towards what people outside their social networks say, such as online reviewers. The study indicates that Word of Mouth or WOM has rapidly grown, supported by the variety of media channels such as social media. Therefore, WOM plays an important role in the decision making of a user. In Malaysia, the development of entrepreneurship has been growing in importance because there is a variety of supporting mechanisms and policies that exist for entrepreneurs, including funding, physical infrastructure, and business advisory services (Ariff \& Abubakar, 2003). Moreover, students in the upper secondary level have been given the opportunity to take elective subjects that are related to the world of entrepreneurship. This is an effort to encourage students to venture into business, to make business a new culture (Mohamed, Rezai, Nasir Shamsudin, \& Mu'az Mahmud, 2012).

Realizing the importance of entrepreneurship, the government has initiated activities and programs related to information technology business among graduates in promoting e-commerce business. Through this effort, the government has been providing financial support to students who wish to become entrepreneurs. With the country's ongoing efforts to become a high-income nation, the practice of creating new businesses using the Internet as a platform, or more commonly known as cyber entrepreneurship, has been established in the Malaysia Plan (2010-2015) (Badaruddin, Arokiasamy, Nordin, Yusof, \& Zakaria, 2012). Furthermore, according to (Egge, Tan, \& Mohamed, 2003), Malaysia is focused on the production of economic transformation into a knowledge-based economy through technology entrepreneurship, in order to increase the contribution of Information Technology and Communication (ICT).

In conclusion, the key reason why entrepreneurs use social media as a business platform to operate their business is that social media can spread information more quickly and easily. Other than that, social media has become a potential persuasive technology that persuades customers to purchase online. Social media also provides interactive conversations between individuals where the users or consumers can share their experiences about the products or services with their friends. Many researchers believe that students may use social media as a start-up strategy to start an online business.

\section{Adoption of Social Media as a Business Platform}

Many researchers have studied about the factors of using social media as a business platform. However, there has been 
little discussion about the adoption of social media as a business platform. The adoption of social media as a business platform can be defined as a practice of applying social media as a tool in operating a business (Bryer, 2011). The adoption of social media as a business platform among student entrepreneurs has become critical in literature review since there is limited research about the adoption of social media. This study will examine the factors that affect the adoption of social media as a business platform including performance expectancy, effort expectancy, social influence, facilitating conditions, and perceived enjoyment.

Indeed, the surge of social media presents a new opportunity for business. The adoption of social media as a business platform creates a new phenomenon in this era. According to Dong-Hun (2010), there are four characteristics that indicate social media as a business platform such as time, cost, audience, and relation. For instance, in time value, the information in social media is distributed quickly and has a long lasting impact in durability compared to the conventional media. The study also states that social media users spread the information that they have received within an hour. Secondly, for audience value, social media transfers the information to a large number of people. It means that social media can transfer and convey the information anytime and anywhere compared to the other media.

Next, the cost value can be reduced with the use of social media. This is because most social media are free of charge and additionally, social media is a low cost way to find a new customer. Lastly, in the relations value, any misinterpretation and confusion may be abolished because the connections in social media are based on adding each other as friends and via interaction (Dong-Hun, 2010).

\subsection{Performance Expectancy and the Adoption of Social Media Usage}

Venkatesh, Morris, Davis, and Davis (2003), defined Performance Expectancy as "the degree to which an individual believes that using the system will help him / her to attain gains in job performance." In this study, Performance Expectancy is about whether student entrepreneurs believe that using social media to operate their online business will improve their performance. The performance on the adoption of social media usage is whether the students get and transform information about their business on time and if they can spread the information faster than the traditional media. The student entrepreneurs believe that the information on social media will motivate them to operate their online business.

There are several studies, which have been found to elaborate the performance expectancy. This construct has been investigated by many researches using the UTAUT model. In India, Gupta, Dasgupta, and Gupta (2008), conducted a research to examine the adoption of Information, Communication, and Technology in a government organization. The result revealed that performance expectancy has a positive impact on the use of ICT. Furthermore, a study to examine the factors affecting the adoption of health information technology in Thailand indicated that performance expectancy is one of the factors that influence health information technology adoption (Kijsanayotin et al., 2009). At the same time, according to Wang (2009), the three constructs derived from the UTAUT model namely performance expectancy, effort expectancy, and social influence, positively influence behavioral intention to use m-learning, consistent with a study by Venkatesh et al. (2003). The results show that performance expectancy is the strongest predictor of behavioral intention to use m-learning, because compared to individuals with lower performance, individuals with higher performance tend to adopt m-learning.

Subsequently, a study to investigate the factors and predictors of internet banking adoption among Malaysians using the UTAUT model by Foon and Fah (2011) revealed that performance expectancy significantly affected behavioral intention towards internet banking adoption. It is consistent with a study that explored the reasons that influence individuals to adopt mobile banking by (Chian-Son, 2012). The result found that performance expectancy has a significant effect on the consumer's intention to adopt mobile banking. Moreover, the research to identify the factors affecting the continuous usage of mobile internet from the perspective of UTAUT and flow theory conducted by Zhou (2011) in China, found that performance expectancy affected the continuous usage of mobile internet. This finding is consistent with a study on digital library usage by Rahman, Jamaludin, and Mahmud (2011) which indicated that the main predictor of intention to use the digital library to study is performance expectancy.

Next, a research to examine the factors that influence the acceptance of m-commerce in Saudi Arabia by Alkhunaizan and Love (2012) proved that performance expectancy has a relationship with behavioral usage intention of m-commerce. Subsequently, a comparative study by Sin Tan, Chong, and Lin (2013) between Malaysia and South Korea, the two fast developing Asian countries, on the factors influencing intention in internet marketing usage proved that performance expectancy had a significant effect on intention in Internet marketing usage for both countries. In Morocco, a study to identify factors influencing e-entrepreneurship by students studying at the national school of business and management, who were considered future entrepreneurs, indicated that performance expectancy influences the 
students' intention to accept e-entrepreneurship positively (Abelmonaim, 2013).

In addition, a study to recognize the factors influencing intention to adopt mobile stock trading among stock investors by Tai and Ku (2013) indicated that performance expectancy significantly affects behavioral intention in mobile stock trading usage. Another study conducted by Escobar et al. (2014) to examine the factors affecting perceived advantages and relevance towards Facebook as a learning tool using the UTAUT Model proved that performance expectancy in the use of Facebook during the teaching/learning process positively affects the perceived advantages of Facebook as a social media platform. In addition, a previous study to determine social media usage and the reasons influencing the acceptance of using social media among health educators proved that performance expectancy has a significant effect on behavioral intention to use social media for health promotion. They believed that social media would improve their performance in health promotion and ensure that they will use social media appropriately (Hanson et al., 2011)

With all these evidences, it is apparent that performance expectancy has a relationship with behavioral intention and usage towards technology adoption using the UTAUT model. Additionally, in the context of operating a business, student entrepreneurs believe that social media will enhance their performance in operating their business. Undeniably, using social media to operate a business will help student entrepreneurs gain benefits such as improved productivity, efficacy, and time saving. Therefore, it is not astonishing to realize that student entrepreneurs use social media as a tool to operate their online business.

\subsection{Effort Expectancy and the Adoption of Social Media Usage}

Effort Expectancy is referred as "the degree of ease associated with the use of the system" (Venkatesh et al., 2003). In this study, this factor is about how easy it is for student entrepreneurs to use social media in operating their business. For instance, the relationship between effort and social media usage is when the student compares how much effort and time it takes to sell the products or service in order to contribute to their business. Over the past few years, there has been a dramatic increase in research on effort expectancy and intention or usage of user behavior. A number of studies have found that effort expectancy significantly affects behavioral intention and usage towards technology adoption in the UTAUT model. This construct has been tested in various studies. Previously, a study by Y. S. Wang, Wu, and Wang (2009) revealed that effort expectancy significantly affected individual intention in M-Learning usage. It means most of the m-learning users think that it will be easy to use, due to details in both hardware and software, for instance the touch screen menus, light pen data entry, handwriting recognition, and natural language processing.

Furthermore, a research on external factors influencing performance of behavior towards intention to act found that effort expectancy significantly affected behavioral intention in IT innovation usage. In addition, it had the tendency to act as a moderator in this research (Moghavvemi, Mohd Salleh, Zhao, \& Mattila, 2012). Moreover, a study conducted by Yu (2012) proved that effort expectancy significantly affected individual intention to use mobile banking. Another study that examined factors influencing intention in mobile stock trading adoption among stock investors by Tai and Ku (2013) stated that effort expectancy also had a significant effect on intention to use mobile stock trading.

Effort expectancy has also been tested in the study of information kiosk users. The study proved that effort expectancy had a significant effect on behavioral intention, which means the kiosk developers need to improve the complexity of hardware or software to make it easier for users to use it (N. Wang, Shen, \& Sun, 2013). A study by Sin et al. (2013) found that effort expectancy had a significance influence on the intention to use internet marketing among South Korean, but not Malaysians because South Koreans tend to use internet marketing more compared to Malaysians. In contrast, the research on $3 \mathrm{G}$ Mobile Communication found that effort expectancy did not have a significant effect on behavioral intention. This is because most technology adoptions propose the influence of "ease of use" on behavioral intention (Wu, Tao, \& Yang, 2008).

A study using a modified UTAUT model by Rahman et al. (2011) on intention to use digital library revealed that effort expectancy positively influenced intention in digital library usage. The relationship between effort expectancy and digital library usage was moderated by gender, age, and experience. Besides, a study conducted by (Abubakar \& Ahmed, 2013) suggests that the factors affecting effort expectancy on behavioral intention in technology adoption is moderated by technology awareness. A study by Abelmonaim (2013) also suggests that effort expectancy influences Moroccan students' intention to accept e-entrepreneurship positively. Furthermore, a study on the impact of the App-Book purchasing behavior of smart phone users in Korea confirms that the hypotheses of UTAUT Model variable are generally supported. The hypothesis that effort expectancy has a positive impact on the purchase intention of the App-Book was verified. The results also found that the age and experience of users moderated effort expectancy and influenced the purchase intention of the App-Book (J.-O. Lee \& Kim, 2013). 
In order to gain a better understanding of effort expectancy towards intention or usage behavior, many investigations about this construct have been done. For instance, a study to investigate the consumers' intention to use eMoney as a micro payment transaction by Khatimah and Halim (2014) proved that effort expectancy has a relationship with intention to use e-Money in Indonesia. At the same time, a study to investigate the factors that affect a person who learns Optimization skills (also known as Optimizer) in Indonesia revealed that effort expectancy had a significant effect towards technology acceptance (optimization skill in search engine) (Rahmawati \& Dhewanto, 2014).

Moreover, a study that compared technology adoption between United States and Korea found that effort expectancy has a stronger effect in US compared to Korea (Im et al., 2011). A recent study in a non-western region to validate the UTAUT Model in online banking behavior found that effort expectancy appeared as a key element in internet banking usage and users' experience was a moderator in the study (Al-Qeisi, Dennis, Hegazy, \& Abbad, 2015). Thus, all these studies on effort expectancy prove that effort expectancy is one of the main constructs in the UTAUT model research. In conclusion, effort expectancy is one of the factors that affect the adoption of social media as a business platform among student entrepreneurs. This is because the student entrepreneurs realize that social media is easy to use compared to traditional media and they believe that they will operate their business with less effort but with more outcomes.

\subsection{Social Influence and the Adoption of Social Media Usage}

Many studies have been done to investigate whether social influence is one of the factors that relates to intention or usage behavior. Several studies have suggested that social influence has a significant effect on intention or usage behavior. According to Alkhunaizan and Love (2012), social influence has a significant influence on behavior intention to use m-commerce in Saudi Arabia. According to Venkatesh et al. (2003), defined social influence "as the degree to which an individual perceives that important others believe he / she should use the new system". In this study, this factor is about whether the students expect that others, such as family, friends, partner, co-workers, relatives, and neighbors, would appreciate using social media. In addition, social influence is the way that student entrepreneurs think and perceive about people who are important to them and whether it reflects their behavior. The relationship between social influence and adoption of social media usage is moderated by gender and race.

In Malaysia, a study on entrepreneur's perception on information technology innovation adoption revealed that it has the tendency to act as a moderator between social influence and behavioral intention (Moghavvemi et al., 2012). Subsequently, a study to investigate the factors that affect individuals in adopting mobile banking in Taiwan was done by (Yu, 2012). Surprisingly, the study revealed that social influence is the main factor in the study of people's intention to use mobile banking. In addition, a study to examine factors influencing intention in mobile stock trading adoption among stock investors by Tai and Ku (2013) stated that gender difference was a moderator between social influence and behavioral intention in mobile stock trading usage (Tai \& Ku, 2013). Since the UTAUT model is formulated by eight past theories, many researchers have argued that the UTAUT model is the best model to study about technology acceptance. A study by Abelmonaim (2013) revealed that social influence had a significant effect on Moroccan students' intention to accept eentrepreneurship while technology awareness was a moderator in that study.

Meanwhile, a study by J.-O. Lee and Kim (2013) found that the age and experience of users moderated social influence and the influence on the purchase intention of the App-Book. Similarly, according to Yang and Forney (2013), there is a positive relationship between social influences and intention to use mobile shopping. Furthermore, Wang (2009) stated M-learning practitioners and educators should be aware of the importance of social influence because when the users start to use it, and become familiar, they will ask people around them to use it as well. The study found that there is a significant effect on usage intention towards m-learning. In addition, age and gender differences are moderators in this study. Similarly, a study on factors affecting the perceived advantages and relevance of Facebook as a learning tool indicates that there is a significant effect between social influence and perceived advantages of Facebook (Escobar-Rodríguez et al., 2014).

Additionally, in the blogging perspective, social influence was found to affect blog usage significantly. The findings showed that users were willing to join blog activities because of their community identification and the blog participants gain a sense of belonging (Hsu \& Lin, 2008). In contrast, a previous study showed that social influence has no relationship with intention on internet marketing usage among Malaysians and South Koreans (Sin et al., 2013). In fact, the users' intention on Internet marketing usage was not influenced by others. However, in this study, social influence will be used as one of the factors affecting the adoption of social media as a business platform. The student entrepreneurs believe that they will be influenced by someone they trust or are important to them in order to operate the business. To conclude, social media is one of the main tools for them in operating their online business. 


\subsection{Perceived Enjoyment and the Adoption of Social Media Usage}

Perceived enjoyment can be defined as "the extent to which the activity of using the computer is perceived to be enjoyable in its own right, apart from any performance that may be anticipated" (Carroll \& Thomas, 1988; Malone, 1982). Meanwhile, according to Liao et al. (2008), perceived enjoyment may be defined as the "degree to which a person believes that adoption of multimedia on demand is interesting and associates adoption with enjoyment". This factor is about whether the student feels enjoyment or excitement while operating their business using social media. The feeling of enjoyment and excitement during adoption of social media usage would increase the motivation among student entrepreneurs to operate online businesses.

For decades, the study on perceived enjoyment has attracted a lot of attention as either an antecedent or a consequence of Perceived Ease of Use (PEOU) (Sun \& Zhang, 2006). According to a study of a virtual workplace system by Venkatesh (1999), perceived enjoyment has a relationship with perceived ease of use. Indeed, the impact of perceived ease of use on behavioral intention is more important in game-based training. Similarly, a study of an online help desk and multimedia system for property management indicated that perceived enjoyment has a significant effect on perceived ease of use (Venkatesh \& Davis, 2000). In contrast, a study of a virtual workplace system by (Venkatesh, Speier, \& Morris, 2002) found that perceived enjoyment has no relationship with behavioral intention, mediated by perceived usefulness, and perceived ease of use.

One of the most significant current discussions in computer usage is perceived enjoyment. Social media is preferable to young people, especially students because they really enjoy and have fun using this kind of applications to communicate. A study conducted by Dickinger, Arami, and Meyer (2008) found that perceived enjoyment of using a mobile service is stronger in attitude and intention compared to perceived usefulness. In addition, a study to determine the context of enjoyment in the study of robotic technology was done by (Heerink, Kröse, Wielinga, \& Evers, 2008). The study confirmed that perceived enjoyment has a significant effect on intention in robotic system usage.

Another study proved that perceived enjoyment has a relationship in terms of Internet usage and in activities such as messaging, browsing, downloading, and purchasing (Teo, 2001). This is consistent with Hsu and Lin (2008), who indicated that the use of Information Technology was influenced by perceived enjoyment. It is proven in a study that ease of use and enjoyment appeared to be important variables in the context of blog usage. The result showed that if users did not perceive enjoyment in blogging, they might not participate in blog activities. Moreover, bloggers would struggle to increase participant's intrinsic motivations such as enjoyment, fun, curiosity, and exploration.

Furthermore, a study on the acceptance of Mobile Social Networking Sites by Guo (2014) revealed that perceived enjoyment has a relationship with behavioral intention towards Mobile SNS and the study showed that both female and male users have the same perception in terms of enjoyment. It means that enjoyment and entertainment is not influenced by gender in Mobile SNS usage. This is supported by Lin and Lu (2011) who indicated that perceived enjoyment is the most powerful factor affecting continued intention to use SNS for women and men. Recently, a study conducted by Kumar (2013) proved that perceived enjoyment has a strong relationship with behavioral intention to use 3G Technology in Shimla, India. Similarly, according to Guo (2014), perceived enjoyment is important in influencing people to use a technology or system. This is because people have the willingness to achieve the entertainment value.

The concept of enjoyment should be further explored. Thus, in this study, perceived enjoyment is one of the key factors affecting student entrepreneurs' adoption of social media as a business platform. The entertainment value such as fun and relaxation could influence the student entrepreneurs' use of social media to operate the online business. In addition, in order to achieve the entertainment value, it is important to use the influence of perceived enjoyment in a social media study (Guo, 2014).

\subsection{Facilitating Conditions and the Depth of Social Media Usage}

Based on Venkatesh et al. (2003), facilitating conditions as "the degree to which an individual believes that an organizational and technical infrastructure exists to support use of the system". This factor is about whether student entrepreneurs' have resources to use the Internet and social media applications. For instance, it includes the infrastructure that would be provided by a university or government, such as electricity, infrastructure, PC, tablet and others. A study by Venkatesh et al. (2003), indicated that facilitating conditions have a direct influence on usage, and it is not mediated by intention. Age and experience are moderators in facilitating conditions' usage where the effect is higher for older workers with experience.

Recently, a study by Escobar-Rodríguez et al. (2014) indicated that facilitating conditions in the use of Facebook positively affected perceived relevance of Facebook as a social media platform. This suggests that students' perception 
about the resources and support available for Facebook users influences the intention to use it. A previous study proved that facilitating conditions are related to the intention to use Internet marketing by both Malaysian and South Koreans (Sin et al., 2013). This is similar to studies on facilitating conditions and behavioral intention to use (Guo, 2014; Khatimah \& Halim, 2014). Furthermore, Yang and Forney (2013) indicated that the effect of facilitating conditions is relevant to consumers with a low level of technology anxiety compared to those with a high level of technology anxiety. Additionally, a study conducted by Yu (2012) proved that facilitating conditions have a relationship with individual behavior of using mobile banking.

In contrast, a study on the adoption of mobile devices/services revealed that there is no relationship between facilitating conditions and the adoption of mobile services (Carlsson, Carlsson, Hyvonen, Puhakainen, \& Walden, 2006). Similarly, a study by J.-O. Lee and Kim (2013) also indicated that facilitating conditions have a negative impact on the purchase behavior of the App-Book. Despite all these evidences, this study believes that facilitating conditions significantly affect the adoption of social media as a business platform. Therefore, facilitating conditions is one of the key factors affecting student entrepreneurs' in the adoption of social media as a business platform.

\subsection{Depth of Adoption of Social Media}

Depth of adoption can be defined as the degree to which the technological capabilities of the installed machines are exploited (Claar, Dias, \& Shields, 2014). For decades, many researchers have studied the technology acceptance model (TAM) on technology adoption. According to Venkatesh, Davis, and Morris (2007), a study on the individual-level technology adoption is one of the most mature streams of information systems (IS) research. Previous study by Huang, d'Ambra, and Bhalla (2002) used TAM to investigate the adoption and usage of e-Government in Australia. The study found that besides perceived usefulness and perceived ease of use, other constructs such as the motivation mechanisms, social norms, and organizational culture should be included to explore the adoption and usage of eGovernment. Next, a research on the adoption of Internet banking in South Africa and Singapore revealed that there is a major difference in the attitude towards technology based on nationality (I. Brown, Hoppe, Mugera, Newman, \& Stander, 2004). Another study by Keat and Mohan (2004) provided evidence to explain the level of acceptance on electronic commerce focusing on the TAM model by adding a new construct that is consumer trust.

Subsequently, a research conducted by Klopping and McKinney (2004) found the main indicator for the modified TAM in e-commerce usage in terms of information and purchasing. This is proven by a study to examine the adoption and acceptance of mobile phone services in Turkey that found full support for TAM (Mao, Srite, Bennett Thatcher, \& Yaprak, 2005). Despite prior evidence from the discussion, undeniably, TAM has been extensively used to examine technology acceptance. However, TAM is only applicable in voluntary conditions. Hence, this constraint is overcome in the UTAUT model, because this model assimilates eight previous models. Thus, this study uses the UTAUT model to better explain the usage of social media as a business platform. Recently, a study conducted by Im et al. (2011) stated that when it comes to technology adoption, U.S. users seem to give more weight to the important features of a technology, such as ease of use and usefulness of the technology than Korean users. For this study, the UTAUT Model is the best model to understand the adoption of social media among student entrepreneurs.

This construct will be a major contribution in this study since the adoption of usage is important in examining the implementation of social media usage as a business platform. Thus, this study focuses on factors that lead to the adoption of social media as a business platform among student entrepreneurs. The literatures on information systems are full of studies that observe technology acceptance within an organization. According to Gupta et al. (2008), "the theories such as Technology Acceptance Model (TAM), Theories of Reasoned Action (TRA), Innovation and Diffusion Theory (IDT) and recently Unified Theory of Acceptance and Use of Technology (UTAUT) have identified factors that affect an individual's intention to use or the actual use of Information Technology". Thus, this is the evidence that people will anticipate in using social media because they believe that social media would enhance their job performance and it would be easy to use coupled with the feeling of enjoyment.

Social media is the best tool that internet marketing firms can apply to grow their business. According to Glaser (2007), social media plays an essential role in this endeavor by reducing time and cost of gathering information about consumers wherever they are. In fact, cost reduction is one of the major objectives in adopting social media as a platform in online business. This is because reducing cost will lead to reduction in price. Moreover, according to (Gupta et al., 2008), since facilitating conditions have a relationship with social media usage, thus, appropriate hardware, software, training, and support should be in place. 


\subsection{Social Media Usage}

Social media is growing in popularity based on the number of users; there has been increasing interest in its potential as a business operating tool (Simões, Redondo, \& Vilas, 2013). In depth usage of technology is a study that looks at students entrepreneurs' use of emerging technologies, focusing on how they use social media to communicate, publicize, and share information about their products or services (Conole, De Laat, Dillon, \& Darby, 2008). This section focuses on how student entrepreneurs operate their business based on experience and their perception of social media as a business platform. Three elements influence social media adoption and the perception of social media as a business platform namely information quality, communication, and advertising. Information quality is provided in the social media application to enhance the business operation. For instance, the student entrepreneurs use social media to promote their products or services in order to operate their business.

Communication can be described as a process that creates a similar thought between message senders and recipients, delivery of the information, and the exchange of ideas (Syarief, 2015). For instance, this includes creating a group on Facebook, making a Facebook advertisement, subscribing to the functions, and others. Social media advertising means to increase the attention of the consumers through social media sites (Goyal, 2013). There are two types of advertising in the Facebook context that is paid advertising and free advertising. The first one is paid advertising, where the advertisements appear on the sides of the profile page or on the home page in Facebook. In this form, the advertisers can customize their advertisements based on their target market according to gender, age, location, and interest. The benefit from the paid advertising is that it is more targeted to the prospective customers. Secondly, free advertising involves companies making a fan page on Facebook and users who like or follow the page according to their favorites. The managers of the social media will update the company's products and services to connect and engage with customers.

\section{Conclusion}

In conclusion, the objective of this paper was to identify the factors contributing to the acceptance of social media as a platform among student entrepreneurs in Malaysia. From the review, it was found that the factors contributing to the acceptance of social media as a business platform are Performance Expectancy, Effort Expectancy, Social Influence, Facilitating Condition, and Perceived Enjoyment. The findings will assist this research in understanding the acceptance of social media as a platform among student entrepreneurs in Malaysia. With this discussion, this study will guide the policy makers to refine the current policies on improving students' participation in economic activities in light of a more liberalized and challenging environment.

\section{References}

Abelmonaim, A. Acceptance of E-entrepreneurship: case of Morocco.

Abubakar, F. M., \& Ahmed, H. (2013). The moderating effect of technology awareness on the relationship between UTAUT constructs and behavioral intention to use technology: A conceptual paper. Australian Journal of Business and Management Research, 3(2), 14-23.

Ahuja, M. K., \& Galvin, J. E. (2003). Socialization in virtual groups. Journal of Management, 29(2), 161-185.

Al-Qeisi, K., Dennis, C., Hegazy, A., \& Abbad, M. (2015). How Viable Is the UTAUT Model in a Non-Western Context? International Business Research, 8(2), p204.

Albarran, A. B. (2013). The social media industries: Routledge.

Alkhunaizan, A., \& Love, S. (2012). What drives mobile commerce? An empirical evaluation of the revised UTAUT model. International Journal of Management and Marketing Academy, 2(1), 82-99.

Ariff, M., \& Abubakar, S. Y. (2003). Strengthening entrepreneurship in Malaysia. Malaysian Institute of Economic Research, Kuala Lumpur, 1-22.

Badaruddin, M. N. B. A., Arokiasamy, L., Nordin, N. M., Yusof, H., \& Zakaria, T. (2012). Cyber-Entrepreneurial Intention Among Business Undergraduates in Instituions of Higher Learning in Malaysia. Paper presented at the Proceeding of 2nd International Conference on Management.

Brown, I., Hoppe, R., Mugera, P., Newman, P., \& Stander, A. (2004). The Impact of National Environment on the Adoption of Internet Banking: Comparing Singapore and South Africa. Journal of Global Information Management, 12(2), 1-26.

Brown, J., Broderick, A. J., \& Lee, N. (2007). Word of mouth communication within online communities: Conceptualizing the online social network. Journal of Interactive Marketing, 21(3), 2-20.

Bryer, T. A. (2011). The costs of democratization: Social media adaptation challenges within government agencies. Administrative Theory \& Praxis, 33(3), 341-361. 
Carlsson, C., Carlsson, J., Hyvonen, K., Puhakainen, J., \& Walden, P. (2006). Adoption of mobile devices/services-searching for answers with the UTAUT. Paper presented at the System Sciences, 2006. HICSS'06. Proceedings of the 39th Annual Hawaii International Conference on.

Carroll, J. M., \& Thomas, J. C. (1988). Fun. ACM SIGCHI Bulletin, 19(3), 21-24.

Chian-Son, Y. (2012). Factors affecting individuals to adopt mobile banking. Journal of Electronic Commerce Research, 13(2), 104-121.

Claar, C., Dias, L. P., \& Shields, R. (2014). STUDENT ACCEPTENCE OF LEARNING MANAGEMENT SYSTEMS: A STUDY ON DEMOGRAPHICS. Issues in Information Systems, 15(1).

Conole, G., De Laat, M., Dillon, T., \& Darby, J. (2008). 'Disruptive technologies','pedagogical innovation': What's new? Findings from an in-depth study of students' use and perception of technology. Computers \& Education, 50(2), 511-524.

Delerue, H., Kaplan, A. M., \& Haenlein, M. (2012). Social media: back to the roots and back to the future. Journal of Systems and Information Technology, 14(2), 101-104.

Dickinger, A., Arami, M., \& Meyer, D. (2008). The role of perceived enjoyment and social norm in the adoption of technology with network externalities. European Journal of Information Systems, 17(1), 4-11.

Dong-Hun, L. (2010). Korean Consumer \& Society: Growing Popularity of Social Media and Business Strategy. SERI Quarterly, 3(4), 112.

Edwards, S. M. (2011). A social media mindset. Journal of Interactive Advertising, 12(1), 1-3.

Egge, K., Tan, W.-L., \& Mohamed, O. (2003). Boosting Technopreneurship through Business Plan Contests: Malaysia's venture 2001 \& 2002 competitions. Paper presented at the Hawaii International Conference on Business: June 18.

Escobar-Rodríguez, T., Carvajal-Trujillo, E., \& Monge-Lozano, P. (2014). Factors that influence the perceived advantages and relevance of Facebook as a learning tool: An extension of the UTAUT. Australasian Journal of Educational Technology, 30(2).

Foon, Y. S., \& Fah, B. C. Y. (2011). Internet banking adoption in Kuala Lumpur: an application of UTAUT model. International Journal of Business and Management, 6(4), p161.

Gaber, H. R., \& Wright, L. T. (2014). Fast-food advertising in social media. A case study on Facebook in Egypt. Journal of Business and Retail Management Research, 9(1), 52-63.

Glaser, M. (2007). Your Guide to Social Networking Online,". PBS MediaShift, August.

Goyal, S. (2013). Advertising on social media. Scientific Journal of Pure and Applied Sciences, 2(5), 220-223.

Guo, Y. (2014). Moderating Effects of Gender in the Acceptance of Mobile SNS-Based on UTAUT Model. Paper presented at the Management of e-Commerce and e-Government (ICMeCG), 2014 International Conference on.

Gupta, B., Dasgupta, S., \& Gupta, A. (2008). Adoption of ICT in a government organization in a developing country: An empirical study. The Journal of Strategic Information Systems, 17(2), 140-154.

Hanna, R., Rohm, A., \& Crittenden, V. L. (2011). We're all connected: The power of the social media ecosystem. Business horizons, 54(3), 265-273.

Hanson, C., West, J., Neiger, B., Thackeray, R., Barnes, M., \& McIntyre, E. (2011). Use and acceptance of social media among health educators. American Journal of Health Education, 42(4), 197-204.

Heerink, M., Kröse, B., Wielinga, B., \& Evers, V. (2008). Enjoyment intention to use and actual use of a conversational robot by elderly people. Paper presented at the Proceedings of the 3rd ACM/IEEE international conference on Human robot interaction.

Hennig-Thurau, T., Malthouse, E. C., Friege, C., Gensler, S., Lobschat, L., Rangaswamy, A., \& Skiera, B. (2010). The impact of new media on customer relationships. Journal of service research, 13(3), 311-330.

Hsu, C.-L., \& Lin, J. C.-C. (2008). Acceptance of blog usage: The roles of technology acceptance, social influence and knowledge sharing motivation. Information \& Management, 45(1), 65-74.

Huang, W., d'Ambra, J., \& Bhalla, V. (2002). An empirical investigation of the adoption of egovernment in Australian citizens: Some unexpected research findings. The Journal of Computer Information Systems, 43(1), 15.

Im, I., Hong, S., \& Kang, M. S. (2011). An international comparison of technology adoption: Testing the UTAUT model. Information \& management, 48(1), 1-8.

Kaplan, A. M., \& Haenlein, M. (2010). Users of the world, unite! The challenges and opportunities of Social Media. Business horizons, 53(1), 59-68.

Keat, T. K., \& Mohan, A. (2004). Integration of TAM based electronic commerce models for trust. Journal of American Academy of Business, 5(1/2), 404-410.

Khatimah, H., \& Halim, F. (2014). Consumers' intention to use e-money in Indonesia based on Unified Theory of Acceptance and Use of Technology (UTAUT). American-Eurasian Journal of Sustainable Agriculture, 8(12), 34-40.

Kijsanayotin, B., Pannarunothai, S., \& Speedie, S. M. (2009). Factors influencing health information technology adoption in Thailand's community health centers: Applying the UTAUT model. International journal of medical informatics, 78(6), 404-416.

Klopping, I. M., \& McKinney, E. (2004). Extending the technology acceptance model and the task-technology fit model to consumer ecommerce. Information technology learning and performance journal, 22, 35-48.

Kumar, S. (2013). The moderating factors of $3 \mathrm{G}$ user acceptance technology in Shimla (India) using UTAUT model. International Journal of Computer Science \& Engineering Technology, 4(6), 670-674.

Lee, H. S. S., Khong, K. W., \& Hong, J. L. Influence of Online Shopping Enjoyment and Trust Towards Purchase Intention in Social Commerce Sites.

Lee, J.-O., \& Kim, Y.-M. (2013). A Study on the Impact of the App-Book Purchasing Behavior of Smart phone Users in Korea. The Journal of Society for e-Business Studies, 18(3), 45-67. doi: 10.7838/jsebs.2013.18.3.045 
Lin, K.-Y., \& Lu, H.-P. (2011). Why people use social networking sites: An empirical study integrating network externalities and motivation theory. Computers in Human Behavior, 27(3), 1152-1161.

Malone, T. (1982). What makes computer games fun? (Vol. 13): ACM.

Mao, E., Srite, M., Bennett Thatcher, J., \& Yaprak, O. (2005). A research model for mobile phone service behaviors: Empirical validation in the US and Turkey. Journal of Global Information Technology Management, 8(4), 7-28.

Mikalef, P., Giannakos, M., \& Pateli, A. (2013). Shopping and Word-of-mouth intentions on social media. Journal of theoretical and applied electronic commerce research, 8(1), 17-34.

Mir, I., \& Zaheer, A. (2012). Verification of social impact theory claims in social media context. Journal of Internet banking and commerce, 17(1), 1-15.

Moghavvemi, S., Mohd Salleh, N. A., Zhao, W., \& Mattila, M. (2012). The entrepreneur's perception on information technology innovation adoption: An empirical analysis of the role of precipitating events on usage behavior. Innovation, 14(2), 231-246.

Mohamed, Z., Rezai, G., Nasir Shamsudin, M., \& Mu'az Mahmud, M. (2012). Enhancing young graduates' intention towards entrepreneurship development in Malaysia. Education+ Training, 54(7), 605-618.

Pew Research Centre, 2014. "Social media updates". Retrieved 29 July 2015 from http://www.pewinternet.org/2015/01/09/social-mediaupdate-2014/

Rahman, A. L. A., Jamaludin, A., \& Mahmud, Z. (2011). Intention to use digital library based on modified UTAUT model: Perspectives of Malaysian postgraduate students. World academy of science, Engineering and technology, 75, 116-122.

Rahmawati, S., \& Dhewanto, W. (2014). TECHNOLOGY ACCEPTANCE OF OPTIMIZATION IN SEARCH ENGINE (INTERNET) AMONG OPTIMIZER IN INDONESIA. Paper presented at the International Conference on Trends in Multidisciplinary Business and Economics Research.

Serarols-Tarrés, C., Padilla-Meléndez, A., \& del Aguila-Obra, A. R. (2006). The influence of entrepreneur characteristics on the success of pure dot. com firms. International Journal of Technology Management, 33(4), 373-388.

Simões, J., Redondo, R. D., \& Vilas, A. F. (2013). A social gamification framework for a K-6 learning platform. Computers in Human Behavior, 29(2), 345-353.

Sin Tan, K., Chong, S.-C., \& Lin, B. (2013). Intention to use internet marketing: A comparative study between Malaysians and South Koreans. Kybernetes, 42(6), 888-905.

Socialbakers.com, 2012. "Malaysia Facebook page statistics". Retrieved 29 July 2015 from http://www.socialbakers.com/statistics/ facebook/pages/total/malaysia/

Sun, H., \& Zhang, P. (2006). Causal relationships between perceived enjoyment and perceived ease of use: An alternative approach. Journal of the Association for Information Systems, 7(9), 24.

Syarief, S. B. A. (2015). The Analysis of Communication between Friends on Social Media towards Purchase Intension (A Study Case of Companies in Entrepreneurship Project of President University, Bekasi, Indonesia). Procedia-Social and Behavioral Sciences, $169,31-42$.

Tai, Y.-M., \& Ku, Y.-C. (2013). Will stock investors use mobile stock trading? A benefit-risk assessment based on a modified UTAUT model. Journal of Electronic Commerce Research, 14(1), 67-84.

Teo, T. S. (2001). Demographic and motivation variables associated with Internet usage activities. Internet Research, 11(2), $125-137$.

Venkatesh, V. (1999). Creation of favorable user perceptions: exploring the role of intrinsic motivation. MIS quarterly, 239-260.

Venkatesh, V., Davis, F., \& Morris, M. G. (2007). Dead Or Alive? The Development, Trajectory And Future Of Technology Adoption Research. Journal of the association for information systems, 8(4), 1.

Venkatesh, V., \& Davis, F. D. (2000). A theoretical extension of the technology acceptance model: Four longitudinal field studies. Management science, 46(2), 186-204.

Venkatesh, V., Morris, M. G., Davis, G. B., \& Davis, F. D. (2003). User acceptance of information technology: Toward a unified view. MIS quarterly, 425-478.

Venkatesh, V., Speier, C., \& Morris, M. G. (2002). User acceptance enablers in individual decision making about technology: Toward an integrated model. Decision Sciences, 33(2), 297-316.

Wang, N., Shen, X.-L., \& Sun, Y. (2013). Transition of electronic word-of-mouth services from web to mobile context: A trust transfer perspective. Decision support systems, 54(3), 1394-1403.

Wang, Y. S., Wu, M. C., \& Wang, H. Y. (2009). Investigating the determinants and age and gender differences in the acceptance of mobile learning. British Journal of Educational Technology, 40(1), 92-118.

We Are Social, 2012. "Social, digital and mobile in Malaysia". Retrieved 10 June 2015 from http://www.wearesocial.org/graphic-internetsocial-indicators-11092104.jpg/

Wu, Y.-L., Tao, Y.-H., \& Yang, P.-C. (2008). The use of unified theory of acceptance and use of technology to confer the behavioral model of $3 G$ mobile telecommunication users. Journal of Statistics and Management Systems, 11(5), 919-949.

Yang, K., \& Forney, J. C. (2013). The moderating role of consumer technology anxiety in mobile shopping adoption: differential effects of facilitating conditions and social influences. Journal of Electronic Commerce Research, 14(4), 334-347.

Yu, C.-S. (2012). Factors affecting individuals to adopt mobile banking: Empirical evidence from the UTAUT model. Journal of Electronic Commerce Research, 13(2), 104-121.

Zhou, T. (2011). Understanding mobile Internet continuance usage from the perspectives of UTAUT and flow. Information Development, 27(3), 207-218. 